\title{
Guerra, violência e memória cultural nas imagens assírias
}

Katia Maria Paim Pozzer*

Resumo: O presente estudo é o resultado de um projeto de pesquisa sobre os baixos-relevos assírios e tem como objetivo discutir a relação de complementaridade entre a cultura material e a visual nas fontes mesopotâmicas, bem como a transmissão e a sobrevivência de elementos estéticos da antiguidade no mundo contemporâneo.

Palavras-chave: Assíria. Guerra. Violência. Arte. Memória cultural.

\section{Introdução}

Segundo a historiografia contemporânea, o chamado império assírio compreende o período situado entre 934 e 605 AEC. Essa denominação está associada à língua falada na região norte da Mesopotâmia, o dialeto assírio. Com raízes antigas que remontam ao II milênio AEC, a dominação assíria se estendeu por vastos territórios, indo da planície do Djezireh ao reino egípcio (JOANNÈS, 2000, p. 10).

\footnotetext{
"Professora da Universidade Federal do Rio Grande do Sul. Doutora em História pela Université de Paris I (Panthéon-Sorbonne) em 1996 e Pós-doutora pela Université de Paris X - Nanterre em 2011. Esta pesquisa foi financiada pelo Conselho Nacional de Desenvolvimento Científico e Tecnológico (CNPq) e pela Fundação de Amparo à Pesquisa do Estado do Rio Grande do Sul (FAPERGS). E-mail: katia.pozzer@ufrgs.br.
} 


\section{Figura 1 - Mapa do Império Assírio}

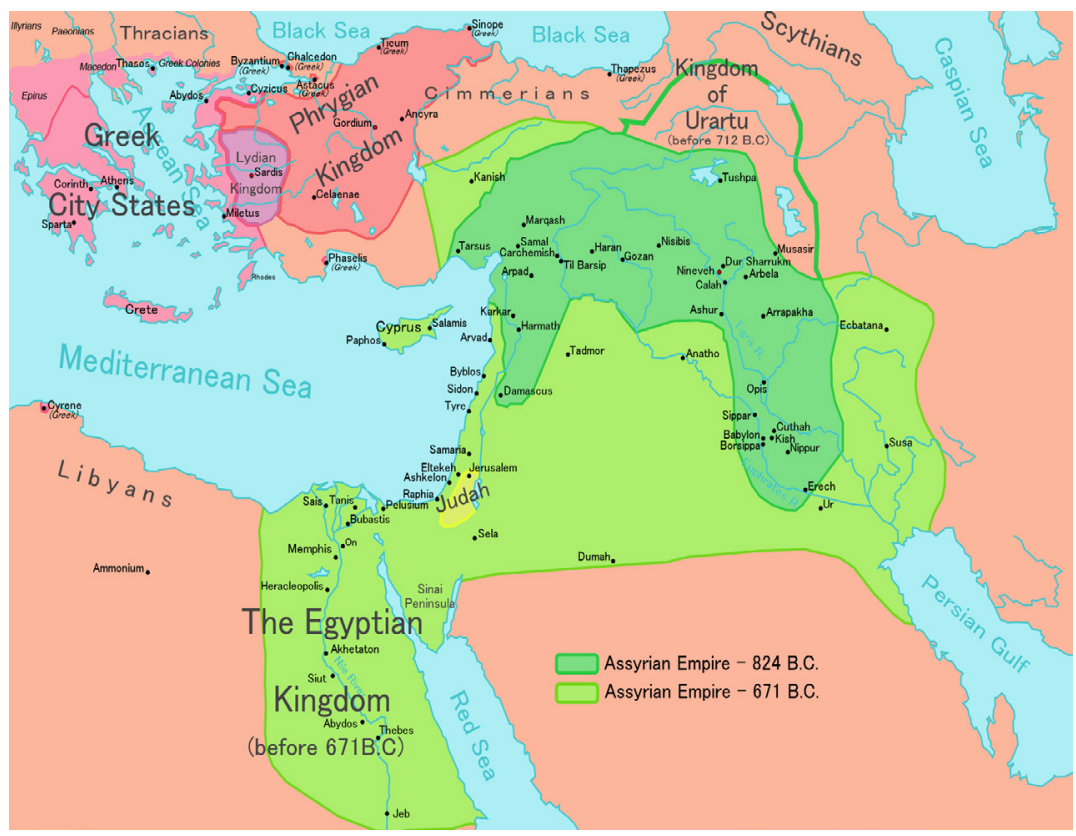

Fonte: Wikimedia Commons ${ }^{1}$

A consolidação da potência militar e expansionista assíria se deu com Sargão II (721-705 AEC), que inaugurou uma nova dinastia e teve como herdeiros os reis Senaqueribe (704-681 AEC), Esarhaddon (680-671 AEC) e Assurbanipal (672-627 AEC) (Figura 1).

Durante o reinado de Senaqueribe, o Estado assírio desenvolveu novas tecnologias de guerra e empreendeu a conquista de territórios da região do Levante, dentre eles a cidade de Lakiš. Em 681 AEC, Senaqueribe morreu assassinado em Kalhu, no templo do deus Ninurta (JOANNÈS, 2000).

Após a sua morte, o reino entrou em colapso com a instauração de uma guerra civil, e, em 680 AEC, ele foi substituído por seu filho, o rei Esarhaddon, que, assim que tomou o poder, atacou o Egito. No entanto, ele morreu precocemente. A sucessão foi garantida pela chegada ao trono de seu filho Assurbanipal (672-627 AEC), que 
imprimiu uma política de guerras expansionistas, até ser derrotado pela coalizão dos exércitos meda e babilônico, em 612 AEC, o que levou à queda definitiva do império assírio.

\section{A Cultura Material na Assíria}

Várias campanhas de escavações, entre os anos de 1852 e 1932, foram realizadas no sítio arqueológico de Nínive, atual território do Iraque. Essas escavações identificaram dois palácios: um localizado a sudoeste, construído por Senaqueribe e conhecido com o "palácio sem rival", e outro na parte norte do sítio, construído por Assurbanipal (RUSSELL, 1997, p. 295).

Figura 2 - Plano do sítio de Nínive

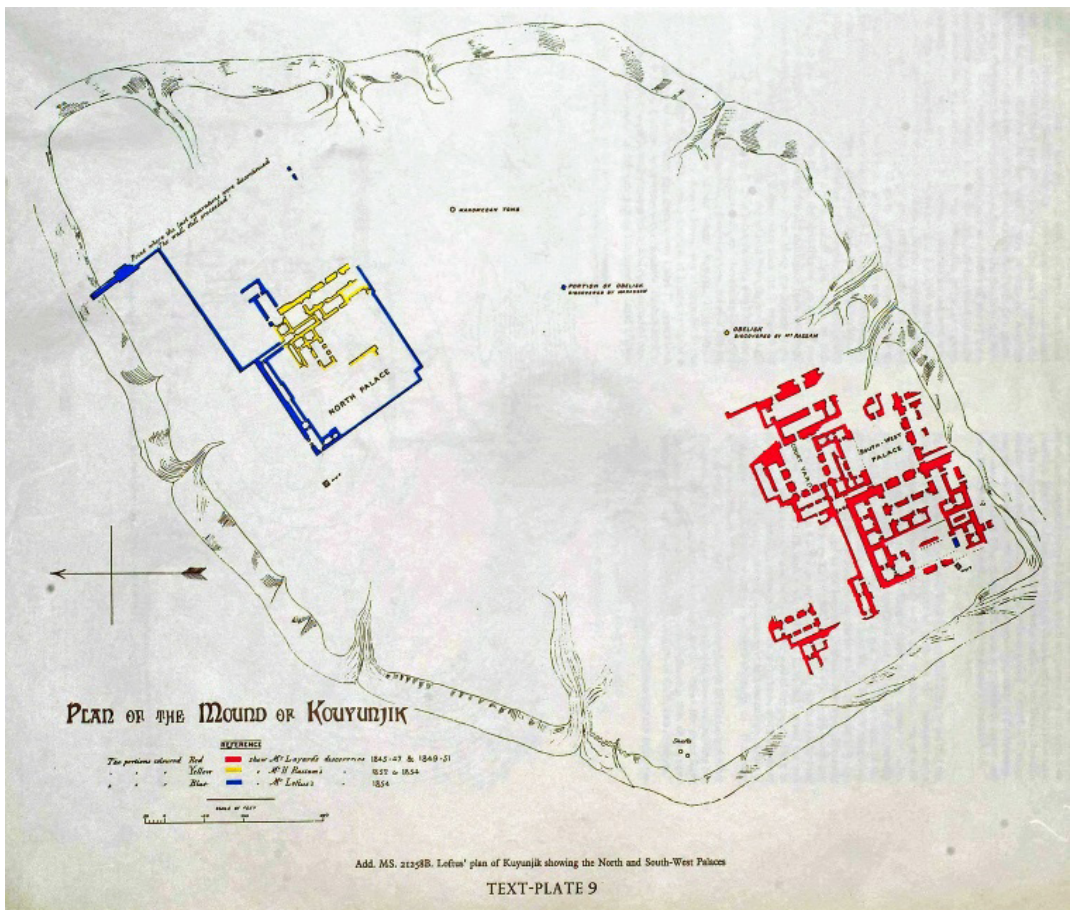

Fonte: BARNETT, 1976, p. 24.

Anos 90, Porto Alegre, v. 25, n. 47, p. 39-59, jul. 2018 
Um dos mais belos conjuntos de baixos-relevos da arte assíria foi encontrado na sala XXVI do palácio sudoeste de Senaqueribe, retratando as representações da conquista da cidade de Lakiš, atual Tell ed-Duweir (Figura 3). Lakiš, construída no século IX AEC pelos reis de Judá, estava localizada na fértil área agrícola de Judá, e fora o centro regional mais influente do governo judaico e a segunda cidade em importância depois de Jerusalém.

Esses relevos, com cerca de $18 \mathrm{~m}$ de comprimento e $2,7 \mathrm{~m}$ de altura, foram descobertos por Henry Layard em 1853, e, atualmente, encontram-se no British Museum, em Londres, na Sala de Lakish. É a série mais longa e detalhada que conhecemos, retratando a conquista de uma única cidade-fortaleza (LAYARD, 1853).

\section{Figura 3 - Relevos de Lakiš}

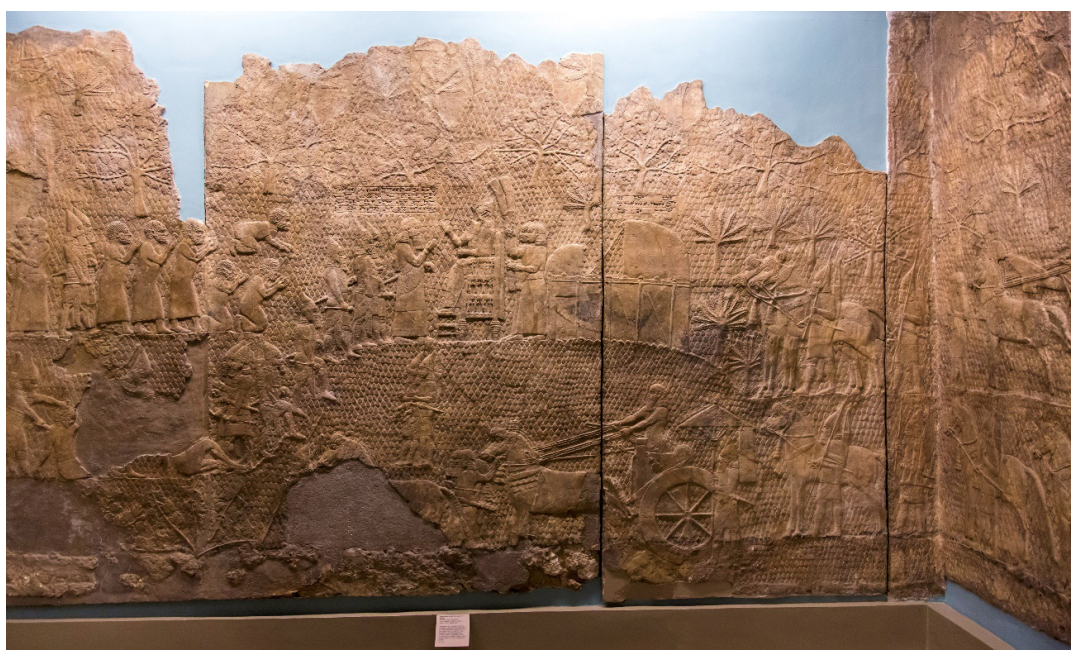

Fonte: Museu Britânico, Londes. Foto da autora, 2017.

Segundo os documentos textuais assírios, essas batalhas teriam o objetivo de conter a revolta palestina, quando uma coalizão composta pelos exércitos do Egito, da Fenícia e da Palestina, sob o comando de Judá, rebelou-se contra o domínio assírio, em 705 AEC. 
Pesquisas arqueológicas na região corroboram essas representações de violência, uma vez que elas identificaram a destruição de várias cidades, como Lakiš, Arad e Beer Shaba.

\section{Figura 4 - Vista aérea de Lakiš}

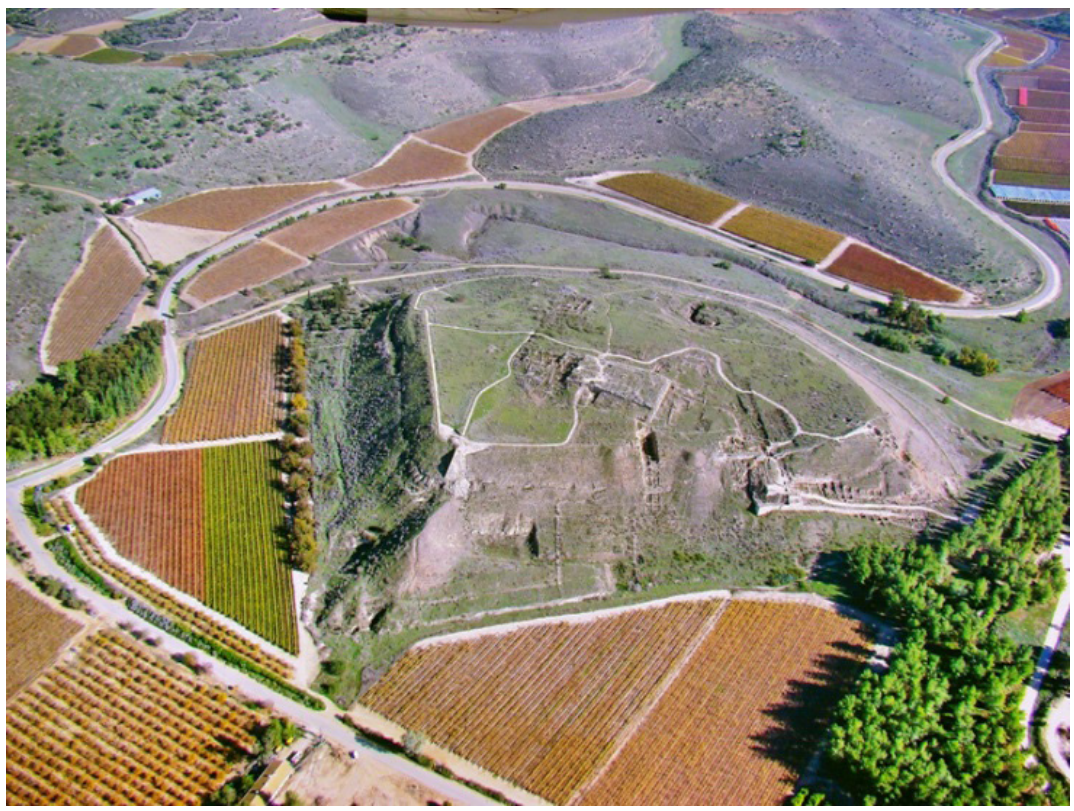

Fonte: Leon Mauldin ${ }^{2}$

Como Lakiš se encontra no alto de uma colina natural, foi necessária a construção de rampas para que o exército assírio pudesse ascender às muralhas da cidade. Isto pode ser evidenciado pela topografia do sítio arqueológico (Figura 4 e 5) e pelas linhas diagonais representadas nos relevos (Figura 6). 
Figura 5 - Sítio arqueológico de Lakiš

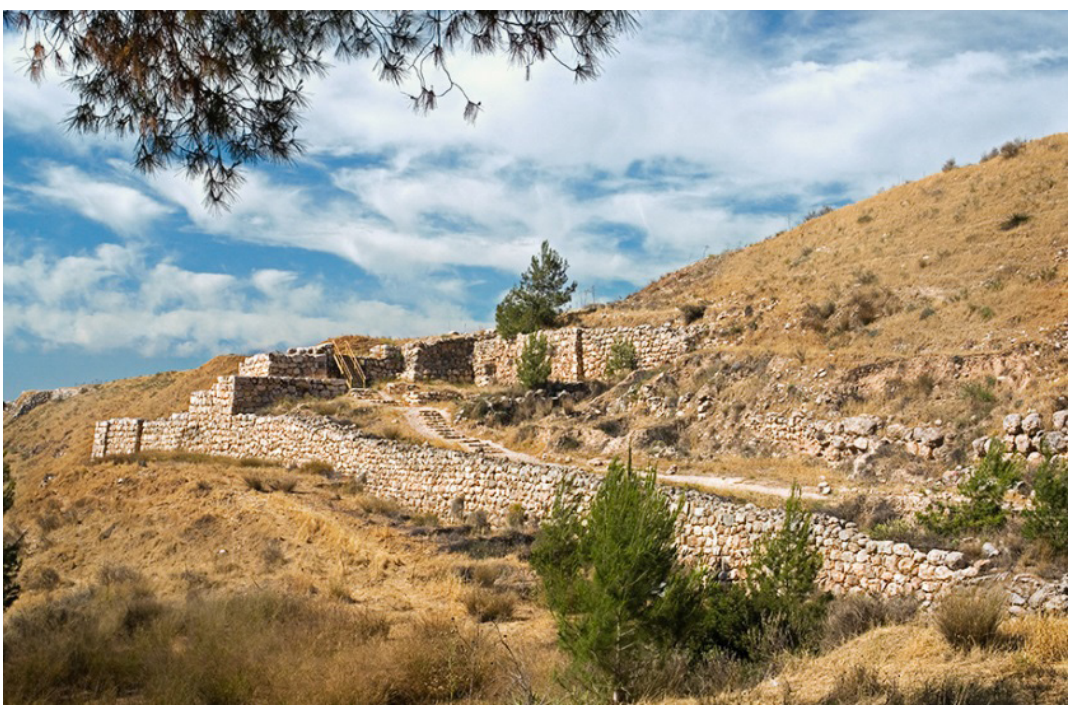

Fonte: Flickr, Foto de Brian Morley

\section{Figura 6 - Detalhe dos Relevos de Lakiš}

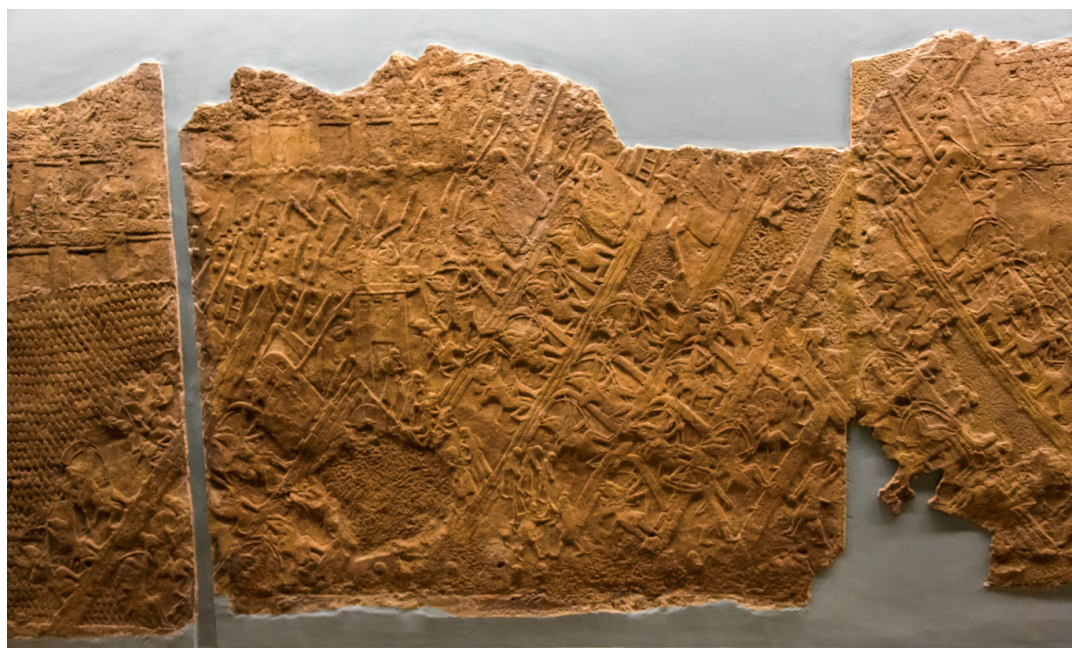

Fonte: Museu Britânico, Londres. Foto da autora, 2017.

Anos 90, Porto Alegre, v. 25, n. 47, p. 39-59, jul. 2018 
A rampa tinha cerca de $70 \mathrm{~m}$ de largura por $50 \mathrm{~m}$ de comprimento, e seu núcleo foi inteiramente feito de pedras recolhidas nos campos ao redor. Estima-se que o peso total das pedras utilizadas na construção da rampa seja em torno de 13.000 a 19.000 toneladas! (USSISHKIN, 2011).

Como afirmam Finkelstein e Silberman (2003, p. 354), as evidências materiais encontradas nas pesquisas arqueológicas no sítio de Lakiš revelam a luta brutal para defendê-la do cerco assírio:

A cidade foi toda queimada [...]. Centenas de pontas de flechas foram encontradas no pé da muralha; enormes pedras arredondadas pela erosão, perfuradas durante o ataque, [...] arremessadas das rampas pelos defensores, para destruir as máquinas assírias de guerra -, foram recuperadas perto do ponto de assalto à muralha. Uma sepultura coletiva, com cerca de 1.500 pessoas - homens, mulheres e crianças -, foi achada nas cavernas perto dos declives no lado oeste do cômoro, misturada com restos de cerâmica do final do século VIII AEC. 
Guerra, violência e memória cultural nas imagens assírias

Figura 7 - Sílex, ou pedra calcária, em forma de bolas, e réplica de uma funda

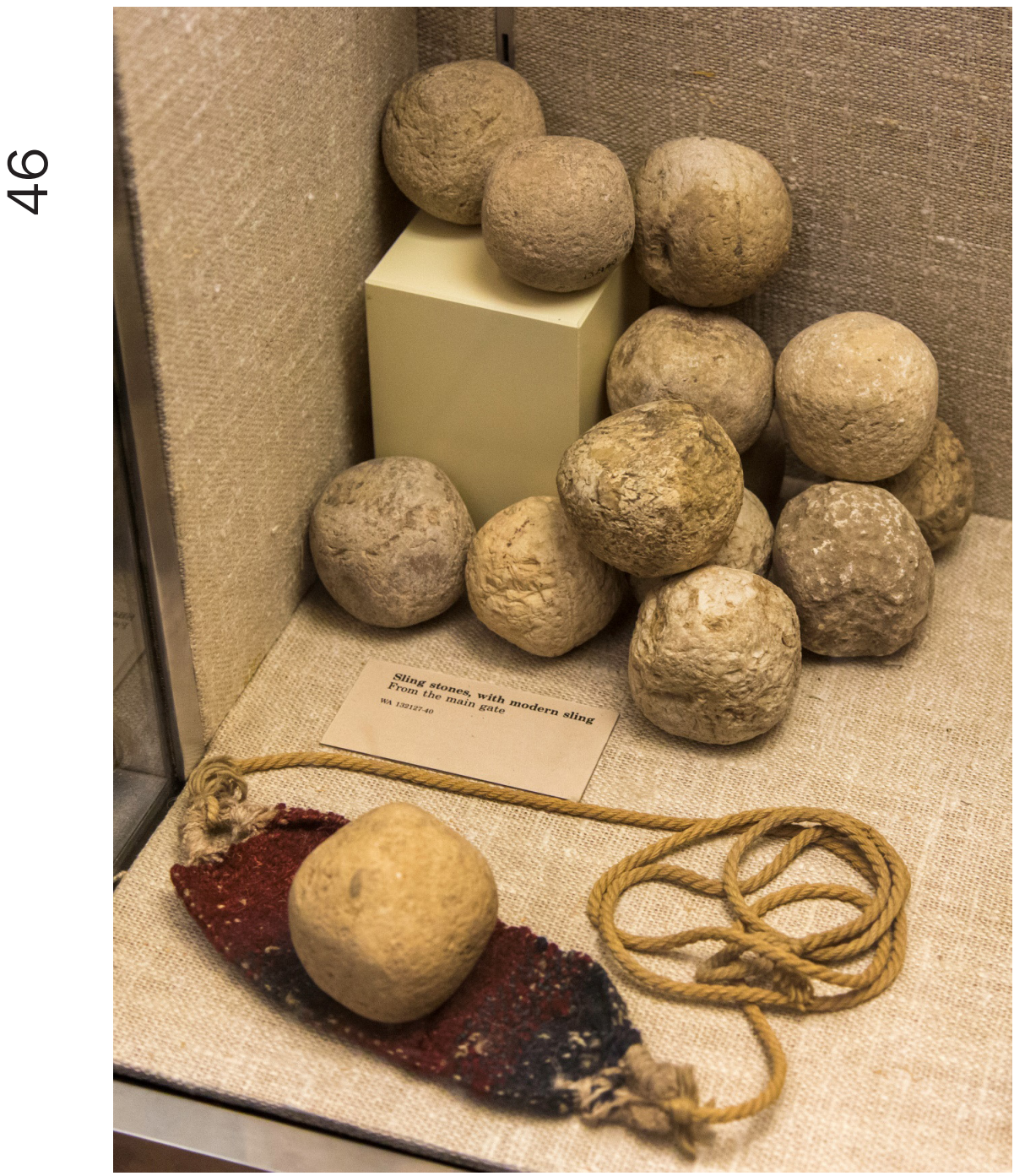

Fonte: Lakišs. Museu Britânico, Londres. Foto da autora, 2017.

Anos 90, Porto Alegre, v. 25, n. 47, p. 39-59, jul. 2018 


\section{Figura 8 - Pontas de flecha em ferro e osso}

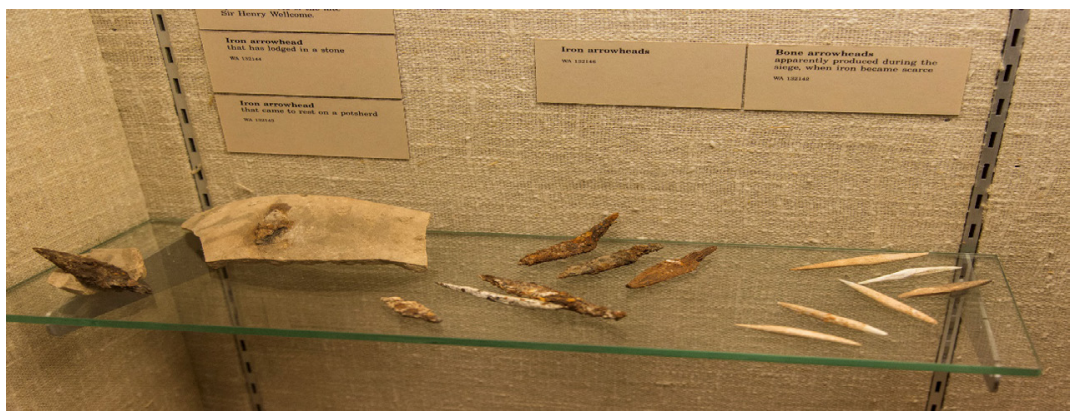

Fonte: Lakiš. Museu Britânico, Londres. Foto da autora, 2017.

\section{A Memória Cultural dos Gestos}

O estudo desses relevos também permitiu-nos identificar um verdadeiro processo de transmissão da memória cultural através da gestualidade de inúmeros personagens.

Como assinala o teórico alemão Jan Assmann (1995, p. 132, tradução nossa), formulador do conceito de memória cultural,

[...] o conceito de memória cultural compreende o corpo reaproveitável de textos, imagens e rituais específicos de cada sociedade em cada época, cujo cultivo serve para establizar e conduzir a auto-imagem daquela sociedade. Sobre tal conhecimento coletivo em sua maior parte do passado, cada grupo baseia sua consciência de unidade e particularidade.

O passado é uma construção social marcada pela necessidade de sentido e de referências de um dado presente. $O$ passado não existe no estado natural, ele é uma criação da cultura. Cultura e sociedade são as condições fundamentais da humanidade para a produção de identidade, seja ela individual ou coletiva, e essa 
identidade é reflexiva, pois ela se dá através da comunicação e da interação com o outro. Na medida em que a identidade pessoal se forma na relação do indivíduo com o outro, é necessário que exista um mundo de sentido simbólico comum, que é a própria cultura. Mas para o homem se adaptar ao mundo de sentido simbólico da cultura, com suas regras e significações, deve existir um distanciamento entre o mundo e si próprio. Assmann (2010, p. 123, tradução nossa) afirma que "A cultura institucionaliza esta distância e que o estabelecimento consciente de uma distância entre si mesmo e o mundo exterior pode ser caracterizada como o ato fundamental da civilização humana”.

Podemos estender essas condições culturais da imagem também ao mundo mesopotâmico, com destaque para os baixo-relevos que, localizados nos palácios, implicavam em perceber a natureza do discurso, compreendendo a fenomenologia da imagem dentro dessa cultura.

A análise desses relevos permite observar distintas unidades do exército, com armamentos e uniformes específicos. Dentre esses, podemos visualizar um grupo de soldados-fundeiros (Figura 9) fazendo uso de uma arma bastante rudimentar... e usada até os dias de hoje (Figura 10), perpetuando a gestualidade do emprego desta arma, magistralmente representada nos relevos. 
Figura 9 - Fundeiros, detalhe dos Relevos de Lakiš

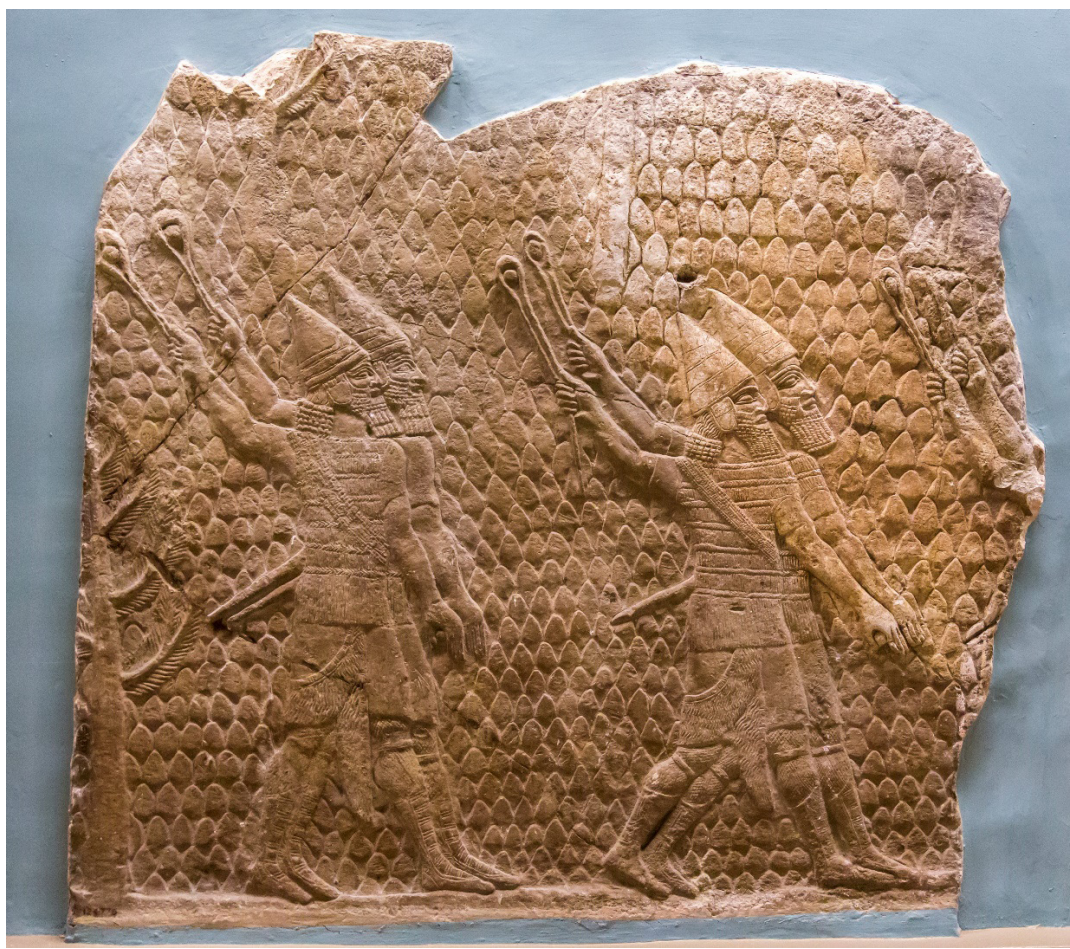

Fonte: Museu Britânico, Londres. Foto da autora, 2017. 


\section{Figura 10 - Jovem palestino usando a funda em protesto contra as tropas de Israel. 2015}

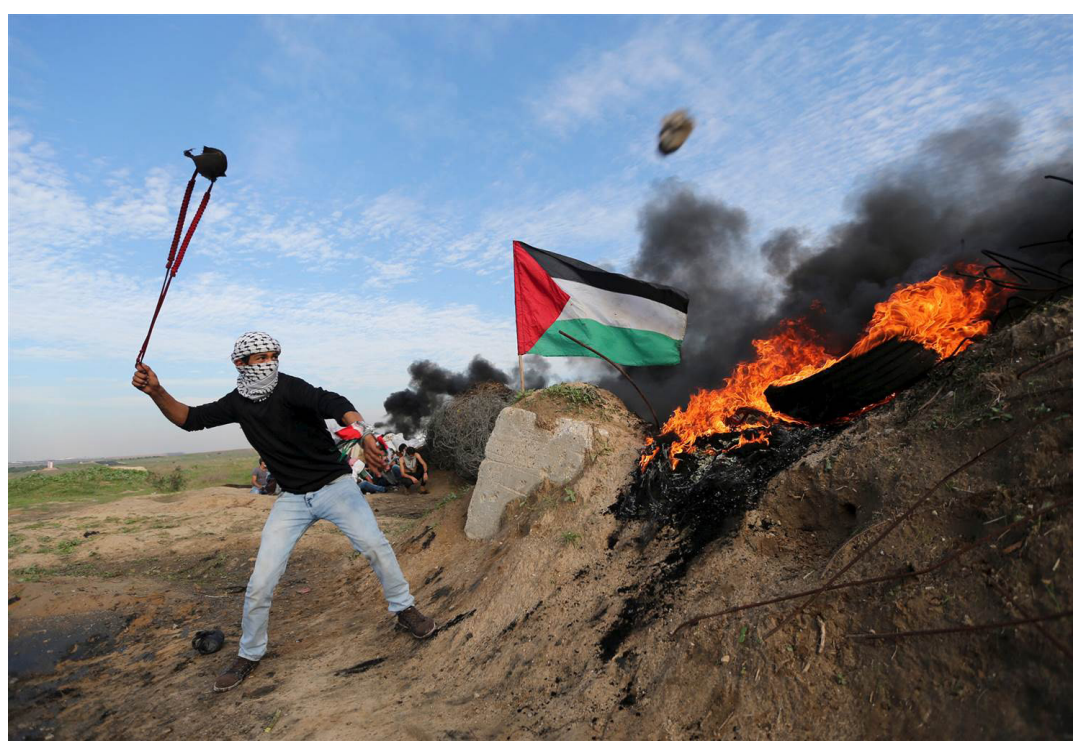

Foto: Ibrahemm Abu Mustafa/Reuters ${ }^{3}$

Mas, além das táticas de guerra, as imagens também revelam a prática de deportação dos prisioneiros, como exposto nas Figura 11 e 12. Nesses detalhes identificamos que os cativos estão sendo conduzidos pelo exército assírio. Vemos um homem carregando uma criança nos ombros, e também algumas mulheres. As mulheres, que raramente são retratadas na arte assíria, são prisioneiras de guerra deportadas, sendo que algumas estão acompanhadas de crianças. $\mathrm{Na}$ linha inferior, vemos homens deportados conduzindo um camelo com pertences e carroças levadas por bois, seguidas de crianças e mulheres. 


\section{Figura 11 - Detalhe dos Relevos de Lakiš}

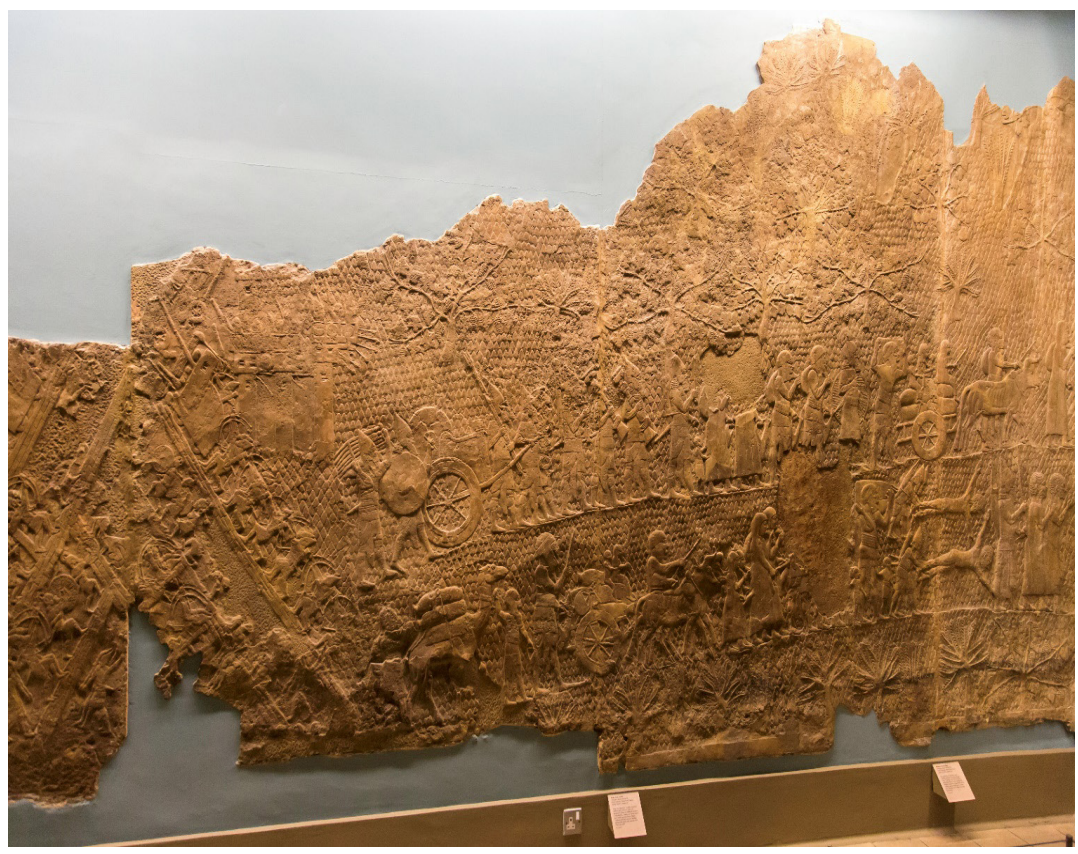

Fonte: Museu Britânico, Londres. Foto da autora, 2017. 


\section{Figura 12 - Mulheres e crianças, detalhe dos Relevos de Lakiš}

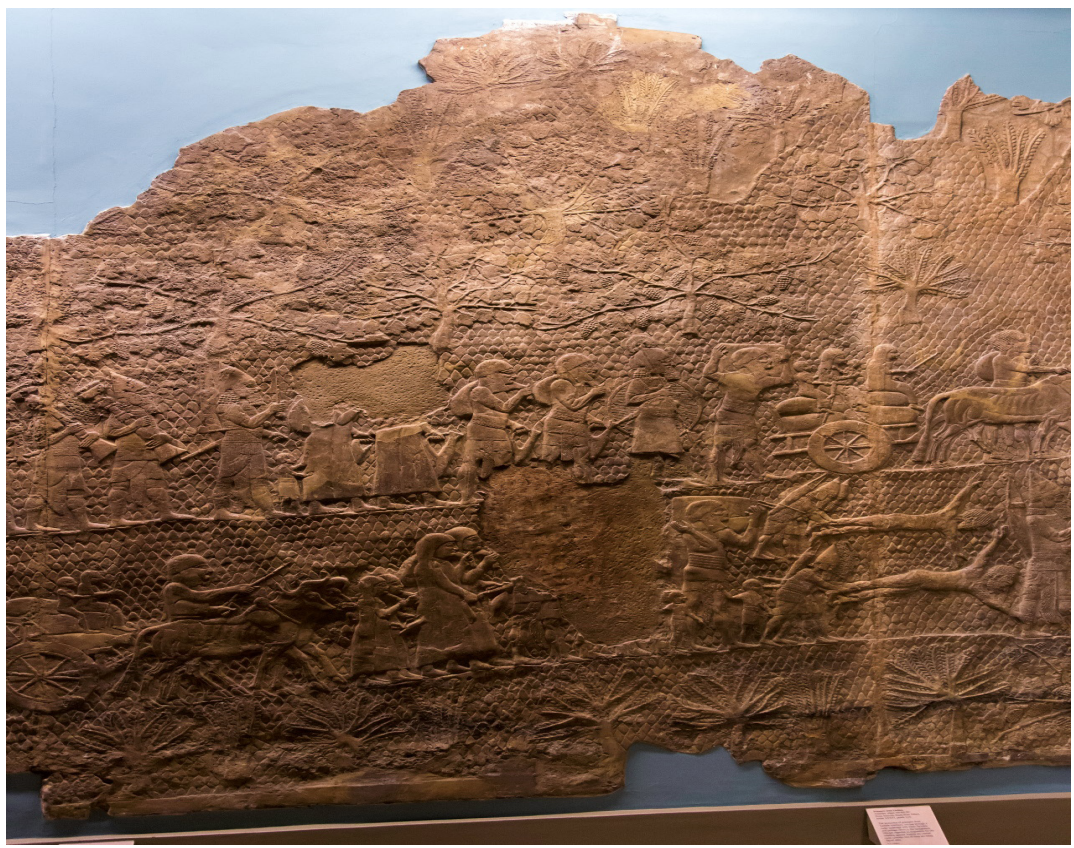

Fonte: Museu Britânico, Londres. Foto da autora, 2017.

Igualmente notável é a similitude encontrada nas imagens do conflito sírio, em 2015. Visualizamos cenas que evocam os deslocamentos forçados e, muitas vezes, os processos migratórios massivos, decorrentes da violência das guerras (Figura 13). 


\section{Figura 13 - Mulher curda com criança nas ruínas de Kobane}

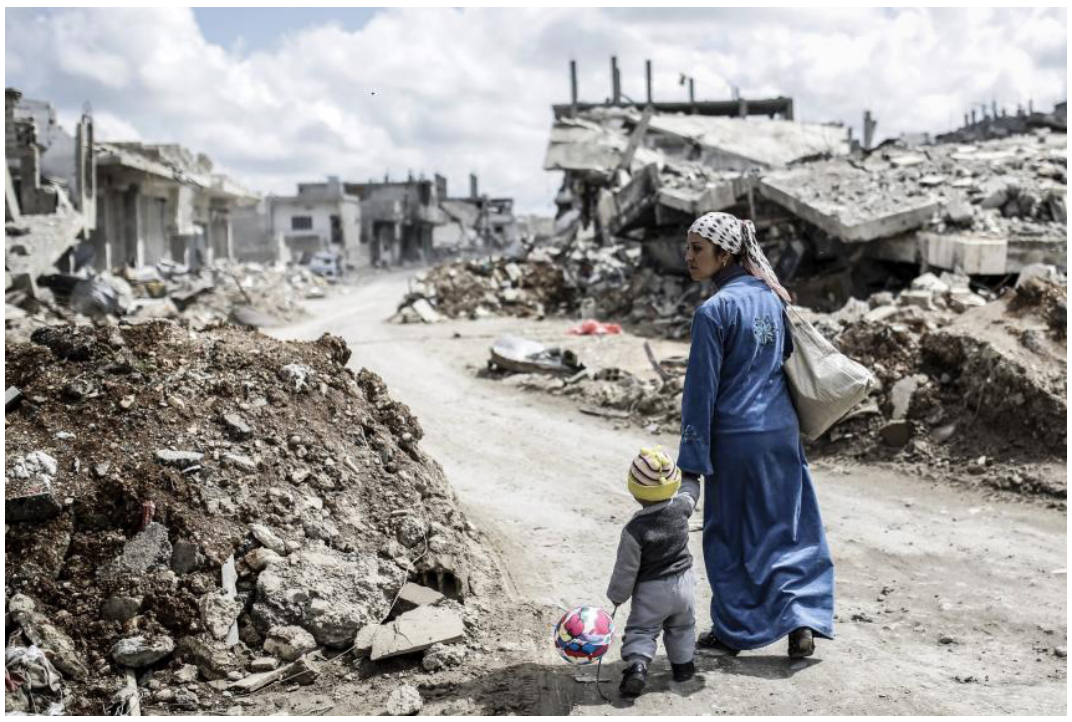

Fonte: Síria, 2015. Yasin Akgul/AFP/Getty ${ }^{4}$

\section{Conclusão}

No ano de 1991, durante a chamada Guerra do Golfo, o governo iraquiano empreendeu uma forte propaganda ao criar e expor outdoors nas principais avenidas das grandes cidades, com a finalidade de buscar o apoio popular à invasão do Kuwait e à iminente ocupação do território pelas forças armadas dos EUA e de seus aliados (que iria se demonstrar catastrófica para todo o Oriente Médio).

Em um desses painéis vemos Saddam Hussein, o ditador iraquiano, caracterizado como um soberano assírio, em seu carro de guerra, empunhando o arco e disposto a enfrentar os inimigos (Figura 14). Zainab Bahrani, arqueóloga e historiadora da arte da Universidade de Colúmbia, Nova York, em seu estudo sobre o corpo e a violência da guerra na Mesopotâmia antiga, defende que, nesse 
caso, a cena tenta mostrar uma imagem da ideologia oficial, mas que, na realidade, ela não passa de uma tentativa de desviar nossa atenção, fazendo-nos cair na armadilha de uma mensagem superficial - a de que Saddam acreditava ser como, ou se parecer com, o herói da antiguidade (Figura 15). A autora garante que ninguém no Iraque acreditava que Saddam era uma reencarnação de Hammurabi $\checkmark \quad$ ou Assurnazirpal II. Para ela, "O subjacente naquele momento era,

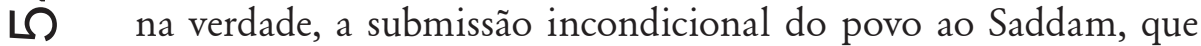
governava o Iraque” (BAHRANI, 2008, p. 73).

\section{Figura 14 - Outdoor de Saddam Hussein}

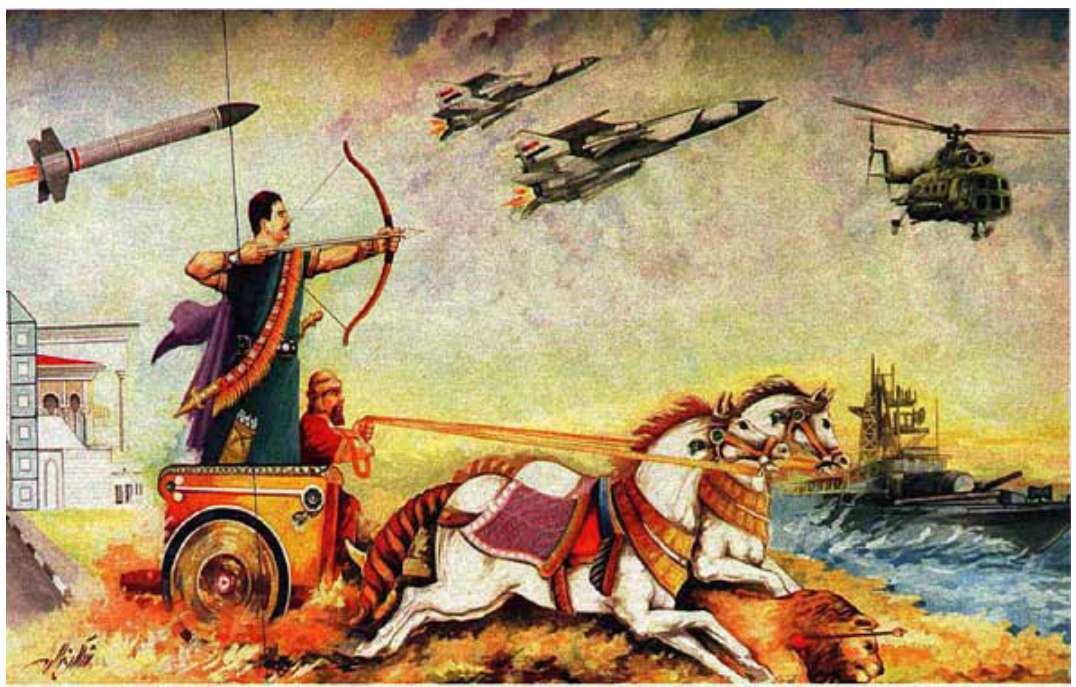

Fonte: Bagdá, 1991. Getty Images. 
Figura 15 - Pintura no Palácio de Til-Barsib. Século VII AEC. $6,40 \mathrm{~m}$ de comprimento

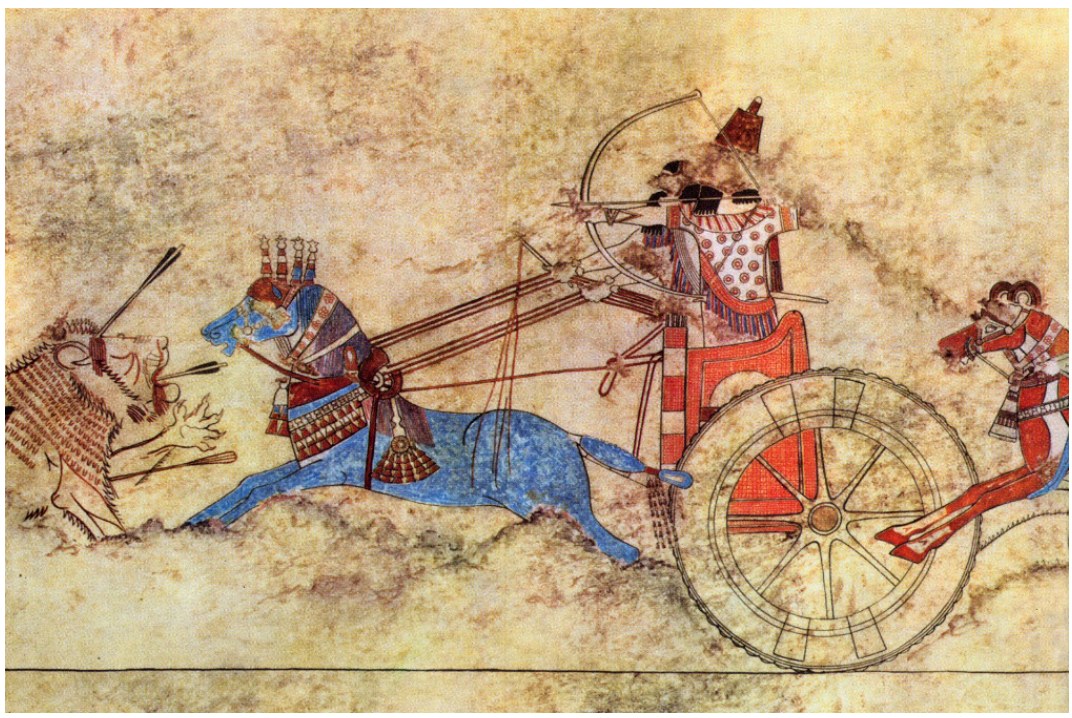

Fonte: PARROT, 2007, p. 250-251.

Zainab Bahrani (2003, p. 121) afirma que o sistema de representação assírio-babilônico é concebido como uma cadeia pluridimensional de aparências possíveis, isto é, que a representação é entendida como uma parte do real. Nesse sistema, a narrativa verbal e a narrativa visual não eram separadas, seus significados estavam imbricados, nos quais ambas possuíam uma relação de interdependência em um mesmo sistema simbólico.

Um sistema simbólico comum permite a formação da identidade coletiva, isto é, a consciência de pertencimento a um grupo social, que depende de um saber e de uma memória comuns. Podemos incluir nesse sistema simbólico não só a linguagem, mas também "ritos, motivos e ornamentos, monumentos, imagens. Tudo pode tornar-se signo para codificar este caráter comum.” (ASSMANN, 2010, p. 125). Nesse sentido, entendemos que o estudo de ícones, 
símbolos e estruturas presentes na arte mesopotâmica é representativo de uma memória coletiva que necessita ser desvendada, e que assim possa explicar suas heranças culturais.

A representação plástica da batalha de Lakiš, feita pelos artistas assírios, retrata os eventos ocorridos e evidenciam um apuro técnico artístico muito grande. Ainda que essas cenas estejam impregnadas de um discurso ideológico e propagandístico, evocando uma íntima relação entre estética e política ou criando uma imagem ilusória, elas não deixam de conter verdades históricas.

Jean-Jacques GLASSNER (1993, p. 111, tradução nossa), que traduziu a série de crônicas assírias - narrativas da história política e militar desse período -, resume brilhantemente a concepção de guerra para eles:

Nesta época, o imperialismo assírio, convencido de sua ideologia universal, assimila a guerra a uma luta contra as forças do mal. Concebida como uma experiência ordálica, a guerra tornou-se um elemento constitutivo da ordem cósmica. Ela salva a população, sendo o rei o instrumento da justiça divina. [...] O estatuto de inimizade e de negatividade do inimigo faz com que as destruições e as devastações adquiram um caráter positivo. $\mathrm{O}$ rei assírio é sempre bom e justo, o inimigo mentiroso, mau e impuro. Os historiadores assírios, servidores zelosos do príncipe, repercutem esta ideologia oficial.

Os artistas assírios transpuseram esse entendimento para as representações imagéticas que ornamentavam os palácios de seus soberanos. E, de maneira significativa, vemos que a transmissão de elementos estéticos e políticos da antiguidade efetuou-se em inúmeras manifestações artísticas do mundo contemporâneo. Ou, ainda, que essa concepção de imperialismo se mostra de grande atualidade quando analisamos os exemplos de conflitos militares em curso, como na Palestina, no Iraque ou na Síria.

Poderíamos compreender essas imagens como um fenômeno de transculturação, o qual engendra uma apropriação de símbolos da antiguidade em um contexto de conflito militar contemporâneo. Ou, 
ainda, que ideologias políticas e determinadas noções plásticas são capazes de se adaptar e sobreviver em condições significativamente diferentes daquelas em que tenham sido originalmente engendradas, permitindo, assim, que o império assírio sobreviva pela força de suas relações simbólicas, estéticas e ideológicas.

\section{WAR, VIOLENCE AND CULTURAL MEMORY IN ASSYRIAN IMAGES}

Abstract: The present study is the result of a research project on the Assyrian bas-reliefs and aims to discuss the complementarity relationship between material and visual culture in Mesopotamian sources, as well as the transmission and survival of aesthetic elements of antiquity in the contemporary world.

Keywords: Assyria. War. Violence. Art. Cultural memory.

\section{Notas}

${ }^{1}$ Disponível em: <https://upload.wikimedia.org/wikipedia/commons/c/c1/ Map_of_Assyria.png>. Acesso em: 5 jul. 2017.

${ }^{2}$ Disponível em: < https://bleon1.wordpress.com/2010/11/30>. Acesso em: 5 jul. 2017.

${ }^{3}$ Disponível em: <https://www.nbcnews.com/news/world/trump-meet-palestinian-leader-abbas-wants-mideast-peace-deal-n753806>. Acesso em: 5 jul. 2017.

${ }^{4}$ Disponível em: <http://www.newsweek.com/sixth-anniversary-syrian-conflict-looms-war-monitor-says-465000-killed-or-567181>. Acesso em: 5 jul. 2017.

\section{Referências}

AMIET, P. Introduction à l'histoire de l'art de l'antiquité orientale. Paris: Desclée de Brouwer, 1979.

ASSMANN, J. Collective Memory and Cultural Identity. New German Critique, Durham, CN, n. 65, p. 125-133, 1995. Disponível em: <http://www.jstor.org/ stable/488538>. 2012. Acesso em: 13 mar. 2012.

. La Mémoire Culturelle: Écriture, souvenir et imaginaire politique dans les civilisations antiques. Paris: Flammarion, 2010. 
BAHRANI, Z. Rituals of War: The body and violence in Mesopotamia. New York: Zone Books, 2008.

. The Graven Image: Representation in Babylonia and Assyria. Philadelphia: University of Pennsylvania Press, 2003.

BARNETT, R. D. Sculptures from the north palace of Ashurbanipal at Nineveh (668-627 B.C.). London: The British Museum Publications, 1976.

BLACK, J.; GEORGE, A.; POSTGATE, N. A Concise Dictionary of Akkadian. Wiesbaden: Harrassowitz Verlag, 2000.

COLLINS, P. Assyrian Palace Sculptures. London: The British Museum Press, 2008 .

CURTIS, J. E.; READE, J. E. Art and Empire: Treasures form Assyria in the British Museum. New York: The Metropolitan Museum of Art, 1995.

FINKELSTEIN, I; SILBERMAN, N. A. A Bíblia não tinha razão. São Paulo: Girafa, 2003.

GLASSNER, J.-J. Chroniques Mésopotamiennes. Paris: Les Belles Lettres, 1993. JOANNÈS, F. La Mésopotamie au 1er millénaire avant J.-C. Paris: Armand Colin, 2000.

Laffont, 2001.

. (Org.). Dictionnaire de la Civilisation Mésopotamienne. Paris: Robert LAYARD, A. H. The Monuments of Niniveh. London: John Murray, 1853.

LIVERANI, M. Para além da Bíblia: História Antiga de Israel. São Paulo: Paulus; Loyola, 2008.

MORRIS, I.; SCHEIDEL, W. (Ed.). The Dynamics of Ancient Empires: State Power from Assyria to Byzantium. Oxford; New York: Oxford University Press, 2009.

OTZEN, B. Israel under the Assyrians. In: LARSEN, M. T. (Ed.). Power and Propaganda: A symposium on ancient empires. Copenhagen: Akademisk Forlag, 1979. p. 251-261.

PARROT, A. Assur. Paris: Gallimard, 2007.

POSTGATE, J. N. Early Mesopotamia. London; New York: Routledge, 1992.

POZZER, K. M. P. Uma História Assíria: o espetáculo do terror em uma composição artística. In: ROSA, C. B.; MARQUES, J. B.; TACLA, A. B.; MENDES, N. M. (Org.). A Busca do Antigo. Rio de Janeiro: Nau Editora, 2011. 
PRITCHARD, J. B. Ancient Near Eastern Texts: Relating to the Old Testament, terceira edição com suplementos. New Jersey: Princeton, 1969.

READE, J. Assyrian Sculpture. London: The British Museum Press, 2006.

ROAF, M. Palaces and temples in Ancient Mesopotamia. In: SASSON, J. M. (Ed.). Civilizations of the Ancient Near East. Peabody: Hendrickson Publishers, 2000. p. 423-441.

RUSSELL, J. M. Sennacherib's Palace Without Rival Revisited: Excavations at Nineveh and the British Museum Archives”. In: PARPOLA, S.; WHITING, R. Assyria 1995. Helsinki: University of Helsinki, 1997. p. 295-306.

. The Writing on the Wall: Studies in the architectural context of Late Assyrian Palace Inscriptions. Winona Lake: Eisenbruns, 1999.

USSISHKIN, D. Excavations and Restoration work at Tel Lachish. Available at: <http://archaeology.tau.ac.il/?page_id=2045>. Access on: 6 dec. 2011.

Recebido: 04/12/2017

Aprovado: 05/02/2018 
